\title{
The DOE/NREL Next Generation Natural Gas Vehicle Program - An Overview
}

\author{
Kevin Walkowicz \\ National Renewable Energy Laboratory \\ Denny Stephens \\ Battelle Memorial Institute \\ Kevin Stork \\ U.S. Department of Energy
}


SAE routinely stocks printed papers for a period of three years following date of publication. Direct your orders to SAE Customer Sales and Satisfaction Department.

Quantity reprint rates can be obtained from the Customer Sales and Satisfaction Department.

To request permission to reprint a technical paper or permission to use copyrighted SAE publications in other works, contact the SAE Publications Group.

This article was prepared as an account of work sponsored by an agency of the United States

Government. Neither the United States Government nor any agency thereof, nor any of their employees, makes any warranty, express or implied, or assumes any legal liability or responsibility for the accuracy, completeness, or usefulness of any information, apparatus, product, or process disclosed, or represents that its use would not infringe privately owned rights. Reference herein to any specific commercial product, process, or service by trade name, trademark, manufacturer, or otherwise does not necessarily constitute or imply its endorsement, recommendation, or favoring by the United States Government or any agency thereof. The views and opinions of authors expressed herein do not necessarily state or reflect those of the United States Government or any agency thereof.

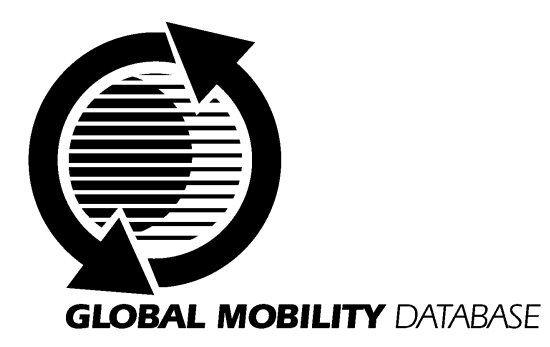

All SAE papers, standards, and selected books are abstracted and indexed in the Global Mobility Database

ISSN 0148-7191

No copyright is asserted in the works of U.S. Government employees.

Positions and opinions advanced in this paper are those of the author(s) and not necessarily those of SAE. The author is solely responsible for the content of the paper. A process is available by which discussions will be printed with the paper if it is published in SAE Transactions. For permission to publish this paper in full or in part, contact the SAE Publications Group.

Persons wishing to submit papers to be considered for presentation or publication through SAE should send the manuscript or a 300 word abstract of a proposed manuscript to: Secretary, Engineering Meetings Board, SAE.

\section{Printed in USA}




\title{
The DOE/NREL Next Generation Natural Gas Vehicle Program - An Overview
}

\author{
Kevin Walkowicz \\ National Renewable Energy Laboratory \\ Denny Stephens \\ Battelle Memorial Institute \\ Kevin Stork \\ U.S. Department of Energy
}

No copyright is asserted in the works of U.S. Government employees.

\begin{abstract}
This paper summarizes the Next Generation Natural Gas Vehicle (NG-NGV) Program that is led by the U.S. Department Of Energy's (DOE's) Office of Heavy Vehicle Technologies (OHVT) through the National Renewable Energy Laboratory (NREL). The goal of this program is to develop and implement one Class 3-6 compressed natural gas (CNG) prototype vehicle and one Class 7-8 liquefied natural gas (LNG) prototype vehicle in the 2004 to 2007 timeframe. OHVT intends for these vehicles to have $0.5 \mathrm{~g} / \mathrm{bhp}-\mathrm{hr}$ or lower emissions of oxides of nitrogen (NOx) by 2004 and $0.2 \mathrm{~g} / \mathrm{bhp}$-hr or lower NOx by 2007 . These vehicles will also have particulate matter (PM) emissions of $0.01 \mathrm{~g} / \mathrm{bhp}-\mathrm{hr}$ or lower by 2004 . In addition to ambitious emissions goals, these vehicles will target life-cycle economics that are compatible with their conventionally fueled counterparts.
\end{abstract}

\section{BACKGROUND}

The transportation sector is dependent on oil for $95 \%$ of its fuel use, resulting in this sector being responsible for $67 \%$ of the total petroleum consumption in the US ${ }^{1}$. The steady increase in the number of vehicles on our roads and the number of miles driven is pushing an everincreasing demand for oil imports. At the same time, worldwide oil reserves are becoming more concentrated in a smaller number of sometimes-volatile countries, leaving the United States vulnerable to potentially serious adverse economic impacts of disruptions in oil supply. The steady increase in vehicles is also contributing to degrading air quality in our cities due to the increasing levels of vehicle emissions.

On-highway medium and heavy vehicles are a large part of our total oil demand with these vehicles being responsible for approximately $18 \%$ of our total onhighway transportation petroleum use in the US ${ }^{2}$. Tailpipe emissions from these vehicles also account for a significant portion of the total emissions from on-highway vehicles in the US. As of 1997, NOx emissions from onhighway vehicles over $8,500 \mathrm{lbs}$. GVW are estimated to be 2.2 million tons annually (31.4\% of all on-highway vehicle NOx emissions) ${ }^{3}$. PM-10 is estimated to be 163 thousand tons annually in the US, and PM-2.5 is estimated to be 142 thousand tons annually resulting in $61 \%$ and $69 \%$ of all PM from on-highway vehicles respectively ${ }^{4}$. Both industry and government have identified a need for clean, fuel efficient, heavy vehicles.

\section{NG-NGV PROGRAM INTRODUCTION}

OHVT has identified the NG-NGV program as an important element in its overall program to reduce oil imports, and vehicle pollutants. Natural gas is a cleanburning, abundant, domestically available fossil fuel. While DOE is 'fuel neutral', it considers natural gas (both in compressed and liquefied form) a promising alternative fuel in terms of cost competitiveness, domestic availability, vehicle performance and low emission of criteria pollutants. Technology developed from this program is expected also to prove beneficial in development and application of other alternative transportation fuels such as hydrogen.

\section{PROGRAM GOALS AND VISION -}

Heavy-duty natural gas vehicles are available today and are demonstrating their potential value in reducing our dependence on foreign oil and reducing criteria pollutants ${ }^{5,6,7}$. However, these vehicles face serious challenges that prevent their widespread acceptance and adoption. Although many efficiencies have been gained, 
these vehicles remain more costly than their conventionally fueled counterparts to purchase and operate. New EPA emissions regulations which begin in 2007 will require both natural gas and conventionally fueled vehicles to have dramatically reduced emissions compared to today's vehicles.

It is OHVT's goal to advance NGV technology for medium and heavy-duty vehicles through the NG-NGV program by commercial implementation of DOEsupported advanced technologies, such as high efficiency natural gas engines, advanced materials, enhanced natural gas fuel storage, and reduced aerodynamic drag. This program will: (1) advance NGV technology through research and development, (2) work to achieve both technical and commercial viability, and (3) help create broader market acceptance and demand for NGV's.

The goal and vision of the NG-NGV program is that one medium-duty (Class 3-6) CNG vehicle and one heavyduty (Class 7-8) LNG vehicle will be available in the 2004 to 2007 timeframe that:

- Advance DOE natural gas and heavy-vehicle technologies

- Implement advanced engine technology

- Represent a significant step change in NGV technology

- Have NOx emission levels below $0.5 \mathrm{~g} / \mathrm{bhp}-\mathrm{hr}$ and PM emissions below $0.01 \mathrm{~g} / \mathrm{bhp}-\mathrm{hr}$ significantly below EPA emissions standards for 2004

- Have NOx emission levels below $0.2 \mathrm{~g} / \mathrm{bhp}-\mathrm{hr}$ and PM emissions below $0.01 \mathrm{~g} / \mathrm{bhp}-\mathrm{hr}$ - at or below EPA emissions standards for 2007

- Are competitive with conventionally fueled vehicles in performance and life-cycle economics

- Are technically and commercially viable

- Aid non-attainment areas in reducing pollutant emissions from vehicles

\section{RESEARCH AND DEVELOPMENT PLAN -}

The objectives and goals outlined above are undoubtedly ambitious. Furthermore, there are numerous questions that need to be answered before specific vehicle development can begin. These questions include:

- What technologies will be needed to accomplish emissions and efficiency goals?

- When can these technologies be available?

- What is needed to implement these technologies and be commercially competitive?

- What are the best vehicles and applications for these technologies to maximize commercial viability?
The NG-NGV program is structured in two phases; the first will focus on answering these basic questions and the second will focus on specific vehicle development.

Phase 1 research is jointly funded by DOE and various state agencies and is expected to accomplish two primary goals by June of CY2002:

(1) Determine the technologies and methods that will be most feasible to control emissions to desired levels and provide maximum fuel economy for the NG-NGV program vehicles and

(2) Develop and evaluate preliminary vehicle designs and market introduction strategies for both targeted vehicles.

Phase 2 will encompass the development, demonstration and testing of the two target vehicles. Phase 2 goals are to

(1) Integrate and prototype selected technologies into a roadworthy Class 3-6 CNG vehicle and

(2) Integrate and prototype selected technologies into a roadworthy Class 7-8 LNG vehicle.

Phase 2 is also planned to be jointly funded by state, federal, and private organizations. This phase may be completed as early as 2004 but could wait until 2007, depending upon the availability and development requirements for emission control and other fundamental technologies. A detailed development strategy and schedule will be developed using the results of Phase 1 .

\section{STAKEHOLDER INVOLVEMENT AND INPUT -}

OHVT recognizes that commercial success of the NGNGV program will require that the vehicles be commercially attractive, that they have a broad customer base and that they be supported by a stable fueling and maintenance infrastructure. OHVT understands that:

- Chassis and engine OEMs will want evidence of a market for these vehicles before they invest and support the program

- The vehicles must be built by industry

- Customers must be included in the development process from the very beginning

Stakeholder participation is a key part of the development and deployment process of the next generation natural gas vehicles and ensuring these criteria for commercial success are achieved. OHVT and NREL have developed a three-element strategy for the active involvement of key stakeholders from both industry and government. These elements are:

(1) Conduct Interactive Industry Workshops: 
Interactive workshops are being conducted in nonattainment venues to identify the most critically needed vehicle technologies. To date, five interactive workshops have been held with involvement from numerous industry and national, state and local government organizations. Workshop participants have identified the following issues as important to the commercial viability of these new vehicles:

- Low life cycle cost

- Competitive initial cost

- Low operating cost to offset initial cost

- Tax credits

- Large, long-term fuel price differential

- Tax credit on fuel used

- Reduced local and state registration and sales taxes,

- SIP incentives

- Infrastructure

- User-friendly refueling infrastructure

- Infrastructure cofunding

- Improved safety during fueling and operation

- Emission credits

- Mobile emission credits

- NOx credits

- Customer satisfaction

- Noise reduction

- Extended warranty

- Access to service/parts over the life of the vehicle

- Mandates

- Fleet rules

- EPACT credits

- Avoidance of lawsuits

Many of these issues are beyond the control of OHVT, NREL and the NG-NGV program. However, issues such as tax credits and infrastructure point to the need to first introduce these vehicles in locations with adequate support for alternative fueled vehicles.

(2) Develop Vehicles with Involvement of an NG-NGV Working Group:

OHVT and NREL have sought the direct involvement and participation of original equipment manufacturers (OEM's) and the natural gas industry through an advisory NG-NGV Working Group. This working group helps:

- Provide experienced, technical guidance in the design and development process

- Encourage acceptance of program plans by OEM's and NGV industry

- Encourage industry support and co-funding

- Provide long-term commitment to vehicle development and marketing by OEM's and the NGV industry
The NG-NGV working group was formed in May of 2000. To date over 60 industry and government representatives have participated and provided valuable insights. This group has been instrumental in developing the comprehensive research and development plan described earlier.

(3) Fueling Infrastructure Support:

A stable and reliable refueling infrastructure will be needed to successfully deploy the targeted vehicles. NREL and DOE, through the NG-NGV program, plan to coordinate the necessary infrastructure enhancements in target markets to ensure successful deployment and market growth. This may include:

- Evaluate the existing infrastructure

- Develop an infrastructure support strategy

- Coordinate the application of the strategy and enhancement of the infrastructure

- Train and support infrastructure personnel

\section{ENABLING TECHNOLOGIES}

Various natural gas vehicle technology development projects have already been initiated with the involvement of the DOE OHVT. Enabling technologies are currently being reviewed by the NG-NGV program for their possible impact and contribution to the NG-NGV vehicles. Implementation of any technology will depend on its performance impact and market feasibility relative to the program vehicles. Although the following is not meant to be a complete list of all technologies that the NG-NGV program is developing or evaluating for implementation, it summarizes the current state of performance of some potential technologies.

\section{ENGINE TECHNOLOGIES -}

- $\quad$ Pilot-ignited natural gas engine (PING):

Dual-fuel engine: Pilot injection is typically $10 \%$ of the total fuel. This amount of injected fuel will limit the NOx reduction capability of the system. These types of engines will require some type of advanced exhaust aftertreatment. More development is needed to achieve NG-NGV goals.

Micro-pilot engine: Micro-pilot injection typically employs $1 \%$ or less of the total fuel in the pilot charge. This lower amount of injected fuel will allow the NOx level to be reduced further than that of a dual-fuel and meet lower NOx levels with less sophisticated exhaust aftertreatment. More development is needed to achieve NG-NGV goals.

- Spark-ignited, lean-burn engine with oxidation catalyst: 
Lean-burn combustion allows for cooler combustion temperatures, which reduces the formation of NOx. Additional development needs to be completed to reduce NOx further. Hydrocarbon emissions are generally higher with these engines and would require some type of advanced catalyst to control them.

- Stoichiometrically fueled, spark-ignited engine with 3-way catalyst and EGR:

Medium-duty natural gas engines currently available could be competitive with gasoline fueled sparkignited engines from an efficiency aspect. These engines could require additional development work to optimize the effect of exhaust gas recirculation (EGR) and a three-way catalyst.

\section{NOx vs Efficiency for Some Typical NG Engines:}

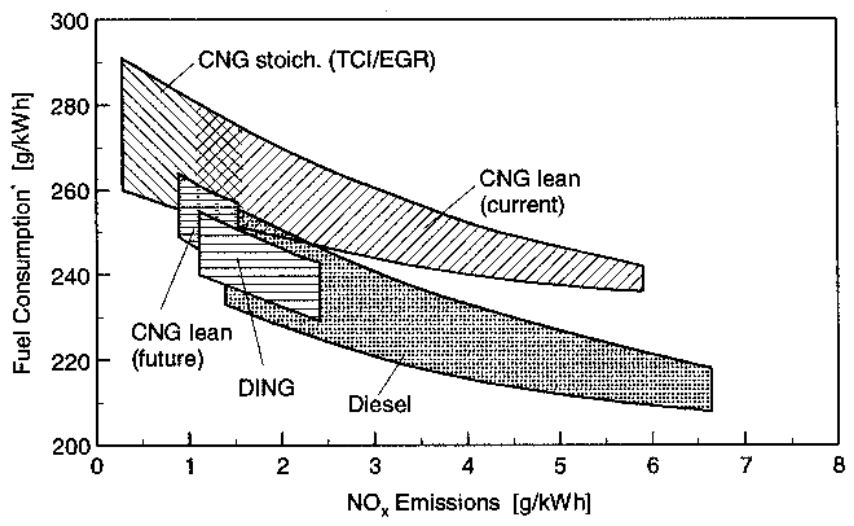

AFTERTREATMENT TECHNOLOGIES -

- Three-way catalyst optimized for natural gas

Three-way catalysts exist for gasoline vehicles today; however, they have not yet been optimized for operation with a natural gas engine with a stoichiometric fuel charge. Improvements could be made which would allow further reduction of emissions while minimizing efficiency losses.

\section{- Lean NOx catalyst}

While some state-of-the art lean-burn natural gas engines emit significantly less NOx than conventionally fueled engines, future NOx emissions standards will require further research and development. However, lean NOx catalysts have a narrow operating-temperature window to achieve the best results. They typically require the addition of another reactant to maintain optimal temperatures and effectively reduce NOx. Further improvements for lean burn natural gas engines are needed.

FUEL STORAGE TECHNOLOGIES -

\section{- Low pressure CNG storage}

Adsorbtion technology stores methane at ambient temperatures in a carbon matrix at significantly lower pressures than conventional CNG. New advances in increasing the storage density of methane in carbon adsorbants at DOE's national laboratories show significant potential in enhancing onboard fuel storage of natural gas. Full scale cylinder demonstrations planned in the near future will enable more detailed evaluation of this technology for use in NG-NGV products.

\section{- Conformable CNG storage}

Conformable storage is another means of more efficient storage of natural gas onboard vehicles. Under DOE funding, conformable fuel tanks have been developed in which multiple cylinders are packaged in a flat tank structure which holds more natural gas in less volume than separate conventional tanks. These technologies will be examined for their potential application to NG-NGV products.

\section{- Low pressure, high density LNG fuel storage}

The density of LNG stored onboard vehicles can be increased by more than 10 percent over current levels if its onboard storage pressure can be reduced to less than $40 \mathrm{psi}$. This will require the development of a reliable and robust method to boost pressure to levels required by engines. This technology is being examined for its potential benefits for the NG-NGV program.

\section{CONCLUSION}

The NG-NGV Program is led by the U.S. DOE's Office of Heavy Vehicle Technologies (OHVT) through the National Renewable Energy Laboratory (NREL). The goal of the program is to develop and implement one Class 3-6 CNG and one Class 7-8 LNG prototype vehicle. The timing of prototyping these two vehicles will be determined by what technology is available to meet the 2007 EPA emissions standards. This determination will be the result of the two-phase program described in this paper. The vehicles developed from this program will enable DOE to achieve its mission of reducing dependence on foreign oil while reducing vehicle emissions to levels as regulated by the EPA.

\section{ACKNOWLEDGEMENTS}

This paper was funded in part under the National Renewable Energy Laboratory which is operated by Midwest Research Institute, Battelle Memorial Institute, and Bechtel for the DOE. The views and conclusions contained in this document are those of the authors and 
should not be interpreted as representing the official policies, either expressed or implied, of the DOE's or of the U.S. Government.

The authors of this paper would also like to thank all of those who have participated in the NG-NGV Working Group and in NG-NGV workshops for their valuable insights and recommendations for this program.

\section{REFERENCES}

1. www.ott.doe.gov/facts/archives/fotw160.html

2. www.ott.doe.gov/facts/archives/fotw158.html

3. www.ott.doe.gov/facts/archives/fotw115.html

4. S.Davis, Oak Ridge National Labs, Transportation Energy Data Book, Edition 19, September 1999.

5. Waste Management's LNG Truck Fleet: Final Results, National Renewable Energy Laboratory, Golden, CO, NREL/BR-540-29073

6. Raley's LNG Truck Fleet: Final Results, National Renewable Energy Laboratory, Golden, CO, NREL/BR-540-27678

7. UPS CNG Truck Fleet: Start-up Experience, National Renewable Laboratory, Golden, CO, in progress.

8. Havenith, C. and Hilger, U., Development Trends for Heavy-Duty Natural Gas and LPG Engines with Respect to Future European Emissions Regulations, Paper No. F98P164, 27th FISITA Congress

\section{CONTACT}

For further information and the latest updates on the NGNGV project please visit the NREL NG-NGV website:

http://www.ctts.nrel.gov/ngngv/ 